\title{
ACOLHIMENTO OU REJEIÇÃO: A INTERPRETAÇÃO COMO RELAÇÃO PROBLEMÁTICA COM A ALTERIDADE - ACERCA DO VERBO ALEMÃO DOLMETSCHEN
}

\author{
Pascal David* \\ Tradução: Bianca Novaes**
}

\section{RESUMO}

Este artigo aborda o problema da comunicação, a denominada "barreira lingüística", a partir de uma reflexão sobre o termo alemão Dolmetscher, que serve para designar aquele que exerce a atividade de tradução, na grande maioria das vezes, da passagem oral de uma língua a outra. Essa atividade é considerada como apenas um dos problemas da comunicação. Por meio da investigação acerca da origem deste termo alemão, enfatiza-se uma dupla vertente relacionada a essa atividade: uma de rejeição, outra de acolhimento. Por um lado, este termo origina-se de vocábulos estrangeiros ao próprio alemão, denotando sua face de rejeição e ressaltando a incomunicabilidade. Por outro, este termo em sua origem designava não apenas o intérprete, mas o mediador ou conciliador entre duas partes adversas, assinalando a sua dimensão de acolhimento.

Palavras-chave: comunicação; interpretação; barreira lingüística; polifonia

\begin{abstract}
ACCEPTANCE OR REJECTION: INTERPRETATION AS A PROBLEMATIC RELATIONSHIP WITH ALTERITY - ABOUT THE GERMAN VERB DOLMETSCHEN

This article approaches the issue of communication, particularly the "linguistic barrier", based upon a reflection on the German term Dolmetscher, which designates an individual that "translates" orally one language to another. This activity is considered only one of several communication problems. By investigating the origin of the German term, we emphasize the double nature related with this activity: one of rejection, and another one of acceptance. On one
\end{abstract}

* Professeur de Philosophie (Université de Bretagne Occidentale, Brest, France).

** Mestre em Teoria Psicanalítica (UFRJ) e Doutoranda em Psicologia Clínica (PUC-Rio). 
hand this term originates from words that are strangers to the German language, highlighting the issues of rejection and non-communicability. On the other, this term, in its origin, designates not only the interpreter, but the mediator between adversary parts, highlighting the acceptance dimension.

Keywords: communication; interpretation; linguistic barrier; polyphony

Para Anne-Marie Couget

Dizia Balzac: "Que belo livro não se comporia, narrando a vida e as aventuras de uma palavra!” (Balzac, [1832] 1980: 28). Sem me lançar aqui na escritura ou na leitura de um romance, eu me contentarei com alguns capítulos ou episódios próprios à vida e às aventuras do termo alemão, hoje usual, que designa o intérprete no sentido da tradução simultânea, ou seja, da passagem oral e simultânea de uma língua a outra. Essa passagem constitui, com efeito, um modo entre outros, mas problemático, de comunicação, na medida em que visa estabelecer uma comunicação entre aqueles que não podem se comunicar por causa da diferença de seus idiomas respectivos. $\mathrm{O}$ intérprete seria, então, um tipo de mediador em uma visita guiada à torre de Babel, onde se origina miticamente a diversidade das línguas, onde os homens não chegam mais a se entender.

O problema da comunicação se coloca, com efeito, a partir de uma radical e fundamental incomunicabilidade (segundo um termo há pouco tempo em voga) da qual a diferença de línguas não é, aliás, senão um dos paradigmas. É o que se costuma chamar: a "barreira lingüística". É por isso que nosso ponto de partida será fornecido por uma situação extrema descrita por Primo Levi ([1986] 1989) em sua obra intitulada Os afogados e os sobreviventes, mais precisamente no capítulo IV intitulado "Comunicar". O autor nele relata uma particularidade lingüística própria ao campo de concentração muito poliglota de Mauthausen, situado na Áustria, perto de Linz, entre Salzbourg e Viena, "Linz" sendo também o nome da... Sinfonia $n^{\circ} 36$ de Mozart. Nesse campo, então, "o chicote era chamado de der Dolmetscher: 'o intérprete', aquele que se faz compreender por todos" (Levi, [1986] 1989: 90). Precisa explicar? É uma concepção inteiramente diferente da interpretação que minha exposição ou, mais amplamente, esse colóquio tentará realizar! Poder-se-ia dizer, de forma muito aproximativa e familiar, em francês, que o chicote é chamado "comme-ça-i'-va-comprendre"

O golpe do chicote intervém aqui como um sinistro substituto daquilo que foi discernido, desde a filosofia grega antiga, como constituindo a dimensão específica e eletiva do ser humano, a saber, a fala. Sinistro substituto quando esta, a 
fala, e com ela o ser humano, se distingue sobretudo por sua inquietante falha. Primo Levi nota precisamente sobre este tema que, em sua lembrança, os primeiros dias passados no campo permaneceram marcados por "um ruído de fundo contínuo e ensurdecedor, mas onde a fala humana não aflorava" (Levi, [1986] 1989: 92). O que é convencionado chamar de "literatura de testemunho" não tem somente um valor documental, tem um valor exemplar acerca de uma interrogação sobre o ser humano. Esse uso lingüístico próprio ao campo de Mauthausen, a saber, no sentido próprio de gíria, Primo Levi comenta da seguinte maneira após tê-lo relatado: "Com efeito, o homem inculto (e os alemães de Hitler, os SS particularmente, eram terrivelmente incultos: eles não tinham sido 'cultivados', ou tinham sido mal cultivados) é incapaz de distinguir nitidamente entre aquele que não compreende sua língua e aquele que não compreende tout court (Levi, [1986] 1989: 91)².

Uma vez que a ironia da língua é, todavia, a de zombar de nós lá mesmo e sobretudo quando acreditávamos tê-la dominado, resta indagar em que o termo Dolmetscher é suscetível de nos instruir sobre o jogo essencial da interpretação entendida como relação problemática com a alteridade - em toda a gama de possibilidades que vão do acolhimento à rejeição. Tendo encontrado nosso ponto de partida em uma situação extrema de rejeição, nós iremos, no momento, tentar reunir o outro pólo, aquele do acolhimento. Pois esse mesmo termo alemão Dolmetscher, do qual acabamos de ver uma sinistra ilustração como figura de rejeição radical, foi inicialmente um tipo de estrutura de acolhimento.

Dolmetscher é em alemão o substantivo do verbo dolmetschen. Tanto o verbo quanto o substantivo são ouvidos por um ouvido alemão, por pouco que seja cultivado, como não soando verdadeiramente alemão, não se deixando vincular a nenhuma raiz, a nenhum prefixo conhecido. É um tipo de Fremdkörper, de corpo estranho. Palavra estranha, então, e efetivamente estrangeira ${ }^{3}$, como nos ensina sua etimologia. É aí que começa o romance. Segundo os dicionários etimológicos da língua alemã de uso corrente que nós consultamos (Duden, Kluge), o termo Dolmetscher, surgido na alta Idade Média alemã (mittelhochdeutsch = do século XI ao século XV, é por exemplo o alemão de Mestre Eckhart), vem do húngaro tolmács, que vem por sua vez do turco tilmacs (cf. romeno talmaci) ${ }^{4}$. Assim, nada há de excepcional no fato de que este termo permaneça inassimilável. É o caso, afinal, do francês, onde truchement (intérprete/tradutor) deve seu nome a um termo árabe que significa precisamente: intérprete. Isso quer dizer que aquele que me transmite o que diz o outro, no fundo, não se denomina, não pode ser denominado em minha própria língua? Que o outro permanece, no fundo, inaudível? Examinemos mais de perto as aventuras do termo alemão dolmetschen. Eu distinguirei quatro etapas, ao fio de quatro observaçóes: 
1) Trata-se, então, de um empréstimo, no sentido lingüístico do termo. O empréstimo, nos diz Albert Dauzat, é "um fenômeno essencial da vida da linguagem: sobre o terreno lingüístico, representa a troca internacional; é o resultado de todas as relações entre os povos" (Dauzat, 1930 : 170). São as próprias relações entre os povos que retornam aqui. Esse empréstimo é um nome emprestado, no duplo sentido da expressão: tomado de alhures, emprestado e pouco natural.

2) As línguas das quais a alta Idade Média alemã fez esse empréstimo (perfeitamente integrado desde a Alemanha moderna) não são apenas línguas estrangeiras, que poderiam ser mais ou menos semelhantes se se tratasse, por exemplo, de línguas germânicas, ou mesmo romanas ou eslavas. Não, o húngaro e o turco (ou magiar e anatólio) são duas línguas que têm, negativamente, em comum, o fato de não serem indo-européias (entre as seis exceções geralmente extraídas do ar indo-europeu, as quatro outras sendo o etrusco, o ibero, o basco e o finlandês) e, positivamente, o fato de representarem os dois ramos do grupo que os lingüistas chamavam, há pouco tempo, "ouro-altaico”. A língua alemã foi, então, de algum modo, buscar para designar o intérprete não somente um termo estrangeiro, mas o mais estrangeiro possível, o menos semelhante possível à língua alemã, ou se quiser, o mais exótico.

3) Esse empréstimo de línguas tão estrangeiras quanto possivel na vizinhança geográfica (a saber, o húngaro e o turco) vem, então, do Império otomano, onde significou, primeiramente, não o intérprete no sentido em que nós entendemos hoje, mas o mediador, o conciliador entre duas partes adversas. O intérprete é, então, antes de tudo, aquele que se interpóe no seio de um mesmo espaço lingüístico (de um mesmo Sprachraum), mas conflituoso, vendo-se investido da temível missão de aí criar ou recriar o laço, um laço certamente bem diferente daquele da violência. Desse simples fato lingüístico verificado por sua proveniência turca via húngaro, é possível extrair, pelo menos, duas lições: de um lado, como todos sabem, não é indispensável que não se fale a mesma língua para que não se compreenda; e, por outro, inversamente, pode-se não falar a mesma língua e, entretanto, ser compreendido. $\mathrm{O}$ intérprete opera nos dois casos. Mas o intérprete que passa de uma língua a outra é, antes de tudo, o mediador no seio de um mesmo espaço lingüístico, de uma mesma língua.

4) Último salto nas peripécias do romance: Lutero escreve em 1530 (2006) um Sendbrief vom Dolmetschen, ou Carta aberta sobre a tradução (dessa vez escrita, e não mais oral), dando caução, assim, ao termo estudado até o momento para designar sua atividade de tradutor da Bíblia. A estranheza, mesmo a inquietante estranheza, não vem mais aqui do húngaro e do turco, mas do hebreu e do aramaico, línguas semitas. Ora, para Lutero, dolmetschen significa: verdeutschen, 
a saber, "alemanizar", "germanizar". Ironia do destino, ou da língua: o termo o menos alemão possível acaba por significar: tornar alemão, fazer falar alemão, aprender a falar alemão, enfim: tornar-se falante de alemão. A saber, de um mesmo golpe, aclimatar alguma coisa de origem estrangeira e exótica. O termo mais estrangeiro possivel vem, paradoxalmente, designar o gesto de apropriação realizado pela operação tradutora. A língua do outro geralmente é imediatamente percebida apenas como balbucio, como barbárie. Em russo, os alemães são chamados de "mudos" (Nêmsty) $)^{5}$, porque seu idioma é tão ininteligível quanto, em Aristófanes, o gorjeio "bárbaro" dos pássaros. Do mesmo modo, em alemão, o termo Kohl, não no sentido de "couve", mas de "galimatias"6, veio a se tornar, por intermédio do iídiche ou judeo-alemão, o hebreu qol, "voz", "língua"7. "É hebreu!", diz-se ainda em francês, sobre algo incompreensível. Razão pela qual o verbo dolmetschen resiste ainda nessa acepção e, às vezes, significa também, em alemão, em certas expressões, alguma coisa como "algaraviar"; o Dicionário dos irmãos Grimm dá como exemplo: "Man versteht nicht was er dolmetscht", ou seja: "não se compreende nada do que ele algaravia".

$\mathrm{O}$ intéprete no sentido aqui considerado relativo à tradução simultânea representa a mais modesta figura, a mais pragmática ou funcional da interpretação. É também a mais desvalorizada, o que, apesar de Lutero, conduzirá mais ou menos à evicção do termo Dolmetscher fora do campo filosófico. Outro paradoxo, pelo menos aparente: o golpe de graça dado por Schleiermacher, pai da hermenêutica, que favorece a desvalorização em sua conferência de 1813 (1999) intitulada Ueber die verschiedenen Methoden des Uebersetzens (Os diferentes métodos de traduzir): "O intéprete (Dolmetscher) exerce seu ofício no domínio da vida dos negócios, o tradutor digno desse nome (der eigentliche Uebersetzer) principalmente no domínio da ciência e da arte" (Schleiermacher, [1813] 1999: 33).

A diferença entre o intérprete e o tradutor não está apenas ligada àquela entre oral e escrito, ela é, sobretudo, índice de classe ou dignidade: o tradutor de artigos de jornais assemelha-se mais, segundo Schleiermacher, ao "simples intéprete" do que ao "verdadeiro tradutor" (Schleiermacher, [1813] 1999: 35). Só mesmo Fichtes Werke ([1813] 2004), parece, para voltar a dar ocasionalmente - no curso desse mesmo ano de 1813 - à noção de Dolmetscher alguns títulos de nobreza na república das letras, qualificando assim o grande sacerdote por ter atuado como intermediário entre os deuses e os homens, eis o Cristo mediador ${ }^{9}$. O que não bastará, todavia, para novamente dourar o brasão do termo, reduzido à sua baixa extração otomana.

$\mathrm{O}$ que concluir de tudo isso? Em que as aventuras da palavra dolmetschen foram instrutivas a respeito dos desafios da questão, certamente bem mais geral, 
da interpretação? A história dessa palavra estranha, e que soube guardar seu coeficiente de estranheza, nos instrui, antes de tudo, sobre o fato de que a interpretação se desenrola em um espaço conflituoso que a diferença das línguas pode certamente exacerbar, mas que está longe de esgotá-lo. O intérprete inter-preta, nós vimos, na medida em que ele se inter-põe. $\mathrm{O}$ intérprete inter-preta como o interdito inter-diz, no sentido próprio e jurídico do termo, a saber: um dizer que se interpõe para acabar com um conflito. A história que evocamos brevemente aqui nos instrui, talvez, igualmente, sobre o fato de que a aprendizagem do próprio para retomar aqui os termos hölderlianos - passa, necessariamente, por um desvio, o desvio pelo que nos é estrangeiro; e o confronto com o que nos é estrangeiro é o que permite, precisamente, a um e a outro se demarcar. À questão "Você é grego?" Hölderlin, autor do "romance grego" Hypérion, teria respondido: "Não, ao contrário, eu sou alemão". Essa essencial "contrariedade" entre o destino grego (antigo) e o destino alemão (moderno) Hölderlin não cessou de experimentar e suportar como um salutar confronto. O estrangeiro, ou melhor, a experiência do estrangeiro, não é, todavia, simples pretexto para a expatriação, mas um desvio necessário para a aceder a si mesmo.

Tendo começado com Balzac, acabaremos com Baudelaire, que nota um dia: "Se, por infelicidade, se compreendesse, não se poderia jamais estar de acordo" (Baudelaire, 1887: 1297). Se há intérpretes, é bem porque os homens não chegam a se entender, donde a necessidade de se falar para tentar dissipar os malentendidos que sempre ressurgem, mas é também porque eles nutrem a louca esperança de chegar um tempo em que se entre em acordo com o outro - como, eu ouso esperar, o tempo desse colóquio polifônico.

\section{REFERÊNCIAS BIBLIOGRÁFICAS}

Balzac, H. de. (1832). Louis Lambert. Paris: Gallimard, 1980.

Baudelaire, C. (1887). Mon cour mis à nu. Paris: Pléiade.

Dauzat, A. (1930). Histoire de la langue française. Paris: Payot.

Fichtes Werke, J. G. (1813). Vocabulaire européen des philosophies. Paris: Seuil/Le Robert, 2004.

Kafka, F. (1912). Discours sur la langue yiddish. In Hochzeitsvorbereitungen auf dem Lande und andere Prosa aus dem Nachlaß (pp. 306-309). Francfort: Fischer Verlag, 1980.

Levi, P. (1986). Les naufragés et les rescapés/Quarante ans après Auschwitz. Paris: Gallimard, 1989. 
Lutero, M. (1530). Carta aberta sobre a tradução. In Clássicos da Teoria da Tradução. Antologia bilingüe, v. 4, Renascimento (pp. 95-115). Florianópolis: NUPLITT, 2006.

Saussure, F. de. (1981). Cours de linguistique générale. Paris: Payot.

Schleiermacher, Fr. (1813). Des différentes méthodes du traduire. Paris: Seuil, 1999.

\section{NoTAS}

1 N.T.: em português, essa expressão seria equivalente a "É assim, e pronto!"; assinala algo pressuposto como evidente, algo compreendido por todos inequivocamente.

2 Saussure (1981) notava, por sua vez: "cada povo crê na superioridade de seu idioma. Um homem que fala uma outra língua é logo considerado como incapaz de falar" (Saussure, 1981: 262).

3 N.T.: a palavra traduzida como "estranha" é uma acepção do termo francês empregado, "étrange". Logo depois a palavra utilizada é "étrangère", que quer dizer "estrangeira".

4 Um amigo de Lausanne assinalou para mim que, do mesmo modo, há a presença do termo "talmacher" (pronuncia-se: "talmatcher") no falar jurassiano, sobretudo no de Jura bernense.

5 Fato enfatizado por Saussure (1981).

6 N.T.: Galimatias é um discurso enredado e confuso, cujo sentido não se pode captar (Koogan/ Houaiss).

7 Sobre as relações "delicadas" que o iídiche mantém com o alemão, reportem-se ao admirável "Discours sur la langue yiddish" pronunciado por F. Kafka em Praga, em 18 de fevereiro de 1912 (Kafka, [1912] 1980).

8 N.T.: algaraviar é falar ou escrever confusamente (Koogan/Houaiss).

9 Fichtes Werke ([1813] 2004), curiosamente, não se interroga, todavia, sobre a etimologia e a história movimentada do termo dolmetschen. Nosso propósito pode, então, ser compreendido como um complemento a essa observação.

Recebido em 21 de fevereiro de 2008 Aceito para publicação em 19 de maio de 2008 